\title{
Microstructural Influence on Erosion Behaviour of Thermal-spray Coatings
}

\author{
B.J.James, ${ }^{*}$ S.J.Matthews, ${ }^{* *}$ and M.M.Hyland** \\ * Research Centre for Surface and Materials Science, University of Auckland, Private Bag 92019, \\ Auckland, New Zealand \\ ** Department of Chemical and Materials Engineering, University of Auckland, Private Bag 92019, \\ Auckland, New Zealand
}

\begin{abstract}
"Thermal spraying" encompasses a range of coating techniques where molten or semi-molten droplets of a coating material are accelerated toward a substrate. Material is built up as a series of "splats". The performance of the resulting coating is a function of microstructure and composition which are, in turn, affected by the spraying parameters.
\end{abstract}

Presented here are results from a study of thermally sprayed $\mathrm{Cr}_{3} \mathrm{C}_{2}-\mathrm{NiCr}$ cermet coatings. The effect of variation of coating splat structure and microstructure on erosion performance has been investigated. $\mathrm{Cr}_{3} \mathrm{C}_{2}-\mathrm{NiCr}$ coatings are used to counter erosion of components under industrial turbine conditions $[1,2]$ namely high temperature, high erodent impact velocity and low erodent flux. During thermal spraying of these materials substantial variation in composition and microstructure occurs due to exposure of the coating powders to the high temperature accelerating gas $[3,4]$. Compositional disorder is trapped within the metastable structure as a result of rapid solidification upon deposition, heat treatment following spraying allows a more stable structure to form. Often coating microhardness is used as an indicator of erosion performance; however, this study has shown the limitations of this practice and the need for understanding and control of the microstructure.

Coating characterisation of high velocity sprayed $\mathrm{Cr}_{3} \mathrm{C}_{2}-\mathrm{NiCr}$ coatings, using $\mathrm{BSE}$ imaging in conjunction with X-ray diffraction, showed carbide dissolution into the matrix of varying extent depending on deposition technique (Figure 1a). Heat treatment at $900^{\circ} \mathrm{C}$ caused rapid carbide precipitation and matrix refinement (Figure 1b), these results are described in detail elsewhere [5]. As can be seen from Figure 2 a microhardness indent "averages" the hardness of both matrix and carbide phases.

Erosion testing of as-sprayed and heat treated coatings was conducted in a custom built apparatus using compressed air to accelerate $20-25 \mu \mathrm{m}$ alumina particles as an erodent. Tests were carried out at ambient and elevated temperature. Erosion rates were measured and single impacts were characterised using SEM in order to determine the erosion mechanism.

At ambient temperature the single impacts caused a brittle response with both carbide grains and matrix being cleaved by the erodent particle. Brittle cracks surrounded each impact and intersected with splat boundaries leading to a significant contribution to erosion rate from splat structure, Figure 3. Following heat treatment the erosion response of the coatings was more ductile with mounds of plastically deformed material surrounding each impact, this significantly reduced erosion rate.

Erosion response at $800^{\circ} \mathrm{C}$ showed more matrix phase ductility, Figure 4; however, heat treatment in this case reduced the erosion resistance of coatings. Heat treatment caused development of a carbide network which constrained the matrix. This meant that even though the matrix was more ductile than at ambient temperatures erodent particles penetrated both phases and generating high lateral loads resulting in displacement of material up and out of the surface. Unlike at ambient temperature the erosion response at high temperature was dictated by the carbide microstructure rather than the coating splat structure. 
References

[1] D.R.Sielski, P. Sahoo, in Thermal Spray: Practical Solutions for Engineering Problems, ASM International, Ohio. (1996) 159-167.

[2] S.T.Wlodek, Proceedings of SPE of Utility Steam Turbines. (1985) 4.43-4.60.

[3] T.Tomita, et al., in Thermal Spray 2001: New Surfaces for a New Millennium, ASM International, Ohio (2001) 699-704.

[4] J.M.Guilemany, J.Nutting, N.Llorca-Isern, J Thermal Spray Technology, 5 n4 (1996) 483-489.

[5] S.J.Matthews, M.Hyland, B.James, J Thermal Spray Technology, 13 n4 (2004) 526-536.
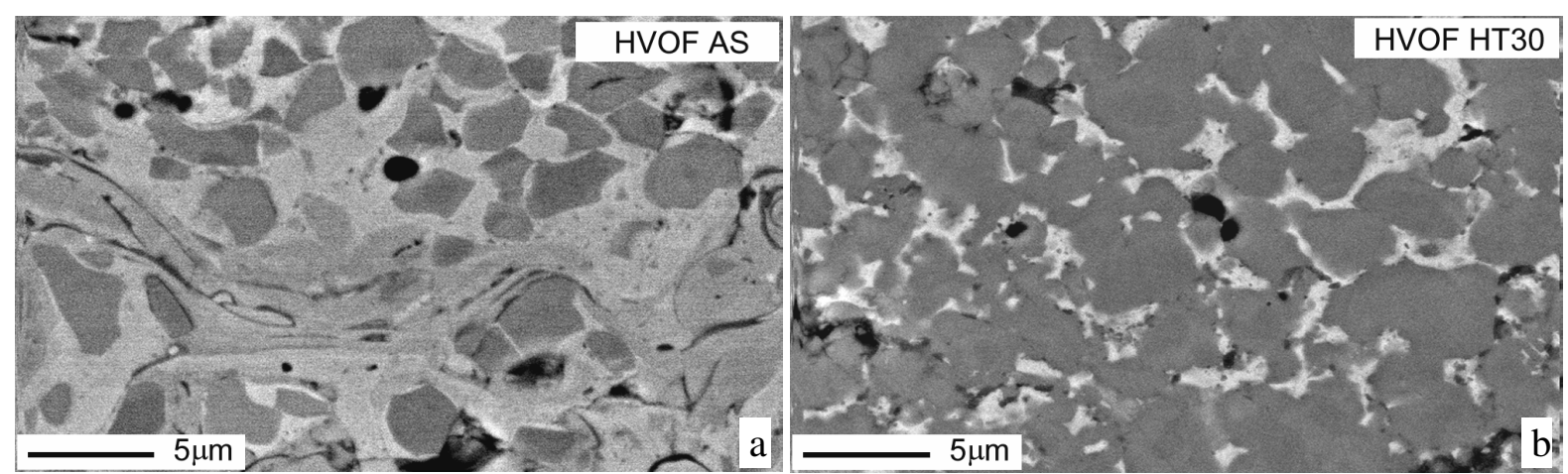

Figure 1: BSE image of as-sprayed (a) and heat-treated (b) high velocity thermal sprayed $\mathrm{Cr}_{3} \mathrm{C}_{2}-\mathrm{NiCr}$ coating. Splat structure is apparent "as-sprayed" and extensive gray scale variation is due to carbide dissolution into $\mathrm{NiCr}$ matrix. Treatment for 30 days at $900^{\circ} \mathrm{C}$ has relieved this meta-stable condition.
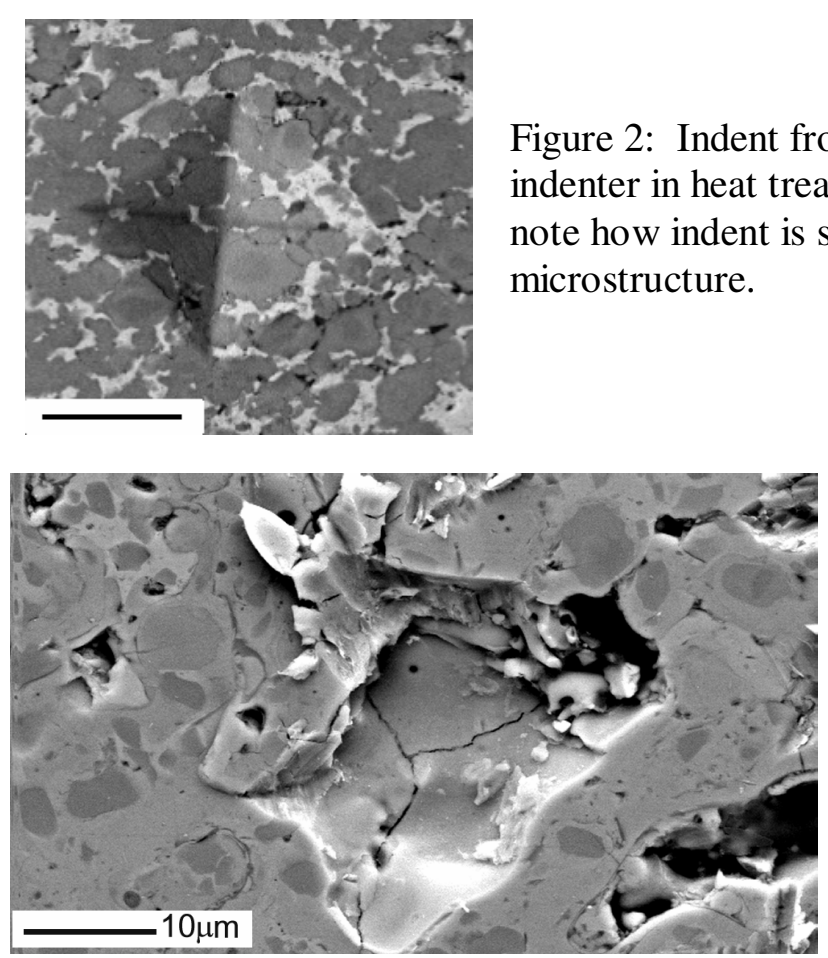

Figure 3: Single impact of erodent particle has introduced brittle cracks into matrix that have intersected with splat boundary (smooth region).

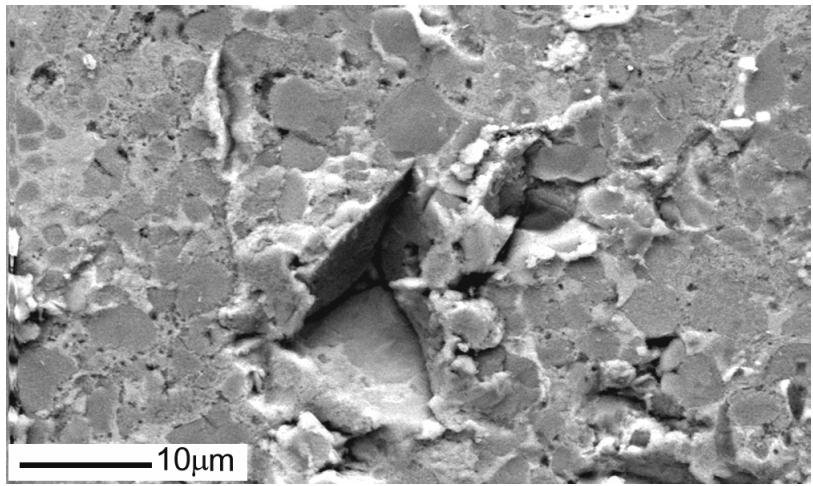

Figure 4: Ductile matrix response to single impact of erodent particle at $800^{\circ} \mathrm{C}$. 